\title{
MORAL Y DERECHO ${ }^{\left({ }_{1}\right)}$ / MORAL AND LAW
}

\author{
Diego Velasco Suárez ${ }^{2}$
}

\begin{abstract}
Resumo
O presente artigo busca entender as relações entre a Moral e o Direito, estabelecendo o que é a Moral, se existe uma lei moral e qual é a sua natureza. O mesmo estudo é desenvolvido no que se refere ao Direito. Por fim, pretende o artigo tentar dar conta das correlações entre Moral e Direito respondendo à pergunta crucial: deve a Moral inspirar as normas jurídicas, ou deve se limitar ao âmbito da consciência individual?

Palavras-chave: Moral. Direito. Relações entre a Moral e o Direito. Consciência individual.

Abstract

This article seeks to understand the relationships between Moral and Law, establishing what is the Moral, if there is a moral law and what is the nature of moral. The same study is developed about the law.

Finally, the article intends to try to account for correlations between moral and law and answering the crucial question: should the Moral inspire legal standards, or should be confined to the individual conscience?
\end{abstract}

Keywords: Moral. Right. Relationship between Morality and the Law. Individual conscience.

${ }^{1}$ Conferencia dictada por, en el Centro Universitario Montefaro, en septiembre de 1992.

${ }^{2}$ Doctor en Derecho y Ciencias Sociales com título en la Universidad de la República de Uruguay. Profesor adjunto de Introducción al Derecho y Derecho Natural en la Facultad de Derecho de la Universidad de Montevideo. Miembro del Instituto sobre Fundamentos de Derecho Internacional Público de la Universidad de Montevideo.

Revista Quaestio luris, vol.04, no01. ISSN 1516-0351 p.329-350 329 


\section{INTRODUCCIÓN:}

El tema de las relaciones entre Moral y Derecho es, ciertamente, uno de los principales de la filosofía del Derecho, riquísimo en consecuencias prácticas y esclarecedor de conceptos fundamentales de esta materia.

Esta importancia es proporcional a su dificultad, pues exige, para su cabal comprensión, profundizar en los términos de la cuestión: ¿qué es la Moral?, ¿qué es el Derecho? Y, para dar respuesta a estos interrogantes, debemos entrar de lleno en la filosofía moral y en la filosofía del derecho.

Por lo señalado, por la limitación de la extensión de este artículo y las mías propias, no pretendo agotar la temática planteada, sino más bien, reflexionar y ordenar algunas ideas fruto de esta reflexión, dejando muchas vías abiertas para una posterior profundización.

En primer término, buscaremos definir qué es la moral, si existe una ley moral y cuál es su naturaleza. Luego, emprenderemos la misma ambiciosa tarea respecto al derecho. Por último, como fruto maduro del trabajo anterior que cae por su propio peso, estaremos en condiciones de abordar, con la luz necesaria, las relaciones entre moral y derecho: ¿debe la moral inspirar las normas jurídicas, o ha de limitarse al ámbito de la conciencia individual?

\section{MORAL: EXISTENCIA Y NATURALEZA DE LA LEY MORAL}

1. Qué es una ley:

Antes de dar una respuesta a la pregunta ¿qué es la ley moral?, debemos responder otra: ¿qué es una ley? Y lo haremos en un sentido más amplio que aquél al que estamos acostumbrados los juristas.

Revista Quaestio luris, vol.04, no01. ISSN 1516-0351 p.329-350 330 
Una ley es una ordenación del comportamiento (del movimiento) de las cosas. Limitaremos un poco más el concepto para referirnos a las leyes naturales. Y diremos que una ley es natural cuando está inscripta en la naturaleza de las cosas.

Para aclarar la definición que acabamos de ensayar, vamos a considerar un tipo de ley natural: las leyes físicas. Sabemos que todos los seres materiales tienen un modo de comportarse uniforme, constante (un orden de su movimiento, es decir, una ley). Así, por ejemplo, todos ellos cumplen la ley de la gravedad, o la de Arquímides, por el sólo hecho de ser materiales. Si observamos el comportamiento de los animales, veremos que, además de aquellas leyes físicas de todos los seres materiales, tienen otras, propias, por ser seres vivos (nacen, crecen, se reproducen y mueren).

Podemos decir, entonces, que las leyes del comportamiento de cada cosa dependerán de lo que esa cosa sea; o que, según el modo de ser que tengan (mineral, vegetal, animal, etc.),

tendrán también un determinado modo de obrar. Y este modo de obrar será, justamente, la ley de su obrar. Por eso es una ley natural, inscripta en su naturaleza (naturaleza es modo de obrar correspondiente a un determinado modo de ser -esencia-; o, lo que es lo mismo, esencia en cuanto principio de operaciones).

\section{Qué es la ley moral:}

$2 \quad$ ¿Cuál es esa ley natural que corresponde al modo de ser del hombre?

Como tiene materia y es un ser vivo, el hombre está sujeto también a las leyes físicas (si lo suspendemos en el aire, caerá, obedeciendo a la ley de la gravedad) y a las propias de los seres vivos (nace, crece, etc.). Pero hay un ámbito de su actividad que responde a la peculiaridad de su modo de ser, que es su actuar libre. Por eso se distingue tradicionalmente entre actos del hombre (regulados por leyes comunes con los demás seres materiales y vivos) y actos humanos -conscientes y libres- que tendrán una ley propia: la ley moral natural.

Revista Quaestio luris, vol.04, no01. ISSN 1516-0351 p.329-350 331 
¿Cuál es el modo de ser del hombre, al que corresponderá un determinado modo de obrar naturaleza- en el que estará inscripta la ley moral?

Aristóteles define al hombre como "animal racional". Esta racionalidad implica un modo de obrar consciente y libre, una inteligencia que descubre el fin de su acción y una voluntad que se mueve hacia ese fin. Vamos a analizar estos dos últimos puntos.

2 La inteligencia humana va más allá de lo inmediato y es capaz de descubrir fines mediatos de su acción y qué es lo conveniente para alcanzarlos. Por ejemplo, un estudiante descubre como fin mediato el recibirse y ve también qué es lo conveniente para ese fin. $\mathrm{Y}$ esta conveniencia es apreciada en abstracto y en concreto. En abstracto, sabe que para obtener el título de abogado debe aprobar determinados exámenes y, para ello, debe estudiar. En concreto, ante una situación en la que se le presenta la disyuntiva de ir a jugar al fútbol o quedarse a estudiar, analizadas las circunstancias del caso (que tiene un examen dentro de tres días), verá cuál es la acción conveniente para alcanzar el fin de recibirse. Y, teniendo en cuenta la regla abstracta de conveniencia, dirá: "puedes ir a jugar al fútbol, porque igual te alcanzará el tiempo para preparar bien el examen"; o: "debes quedarte a estudiar". La inteligencia, en este caso, está actuando como juez: tiene a la vista la regla abstracta de conveniencia y la aplica a la situación concreta, dictando, por último, una sentencia.

Estas reglas de conveniencia de las acciones al fin son normas del comportamiento humano, son leyes en virtud de las cuales se ordena su actuar. Y

son leyes objetivas. La inteligencia sólo descubre, no inventa, que para alcanzar un título universitario hay que estudiar, y luego la aplica al caso concreto.

El hombre hace suya la acción de estudiar, la ve como conveniente para él. En esta calidad, la inteligencia se la presenta a la voluntad. Esta podrá seguir o no la indicación de la 
inteligencia, pero no por eso se cambia la regla (para recibirse sigue siendo conveniente estudiar).

¿Por qué frente a la alternativa de dos fines (obtener el título de abogado o divertirse jugando al fútbol) uno quedó subordinado al otro? Porque vio uno de ellos como más importante (más perfecto), capaz de darle una mayor felicidad. Hay una relación directa entre la perfección de un fin y la capacidad de satisfacer la felicidad de quienes lo alcancen. Así, aunque el ejemplo sea burdo, da mayor felicidad comer una buena torta que un caramelo, y más todavía el terminar una carrera universitaria (uno queda más feliz, más "realizado"). Como el hombre tiene una tendencia íntima, radical, a la mayor felicidad posible (nadie puede no querer ser lo más feliz que pueda), subordina los distintos fines en función de la capacidad que tengan para colmar sus ansias de felicidad, es decir, de su mayor perfección.

Ahora bien, uno no suele tener como último fin de su vida el recibirse. Podríamos preguntarnos: "¿para qué quiero recibirme?" -"Para poder ejercer la profesión de abogado, para poder trabajar"...-"¿Y para qué quiero trabajar?"...Si siguiéramos esta cadena de "para qué", llegaríamos a que todos tenemos un último fin de nuestras vidas. Ese fin, subjetivamente, no puede ser otro que la máxima felicidad posible (por esa tendencia íntima radical que, ya vimos, no admite excepción). Y, objetivamente, por la conexión entre la perfección de un fin y su capacidad de dar felicidad, no puede ser otro que el ser (el ente) más perfecto. Sin embargo, esta coincidencia objetiva puede disociarse subjetivamente: el hombre puede buscar la mayor felicidad en algo que es incapaz de dársela.

2 Volvemos ahora al ejemplo del estudio para reemplazar los términos y aplicarlo a la explicación de la ley moral. Así como el hombre, con su inteligencia, es capaz de descubrir qué es lo conveniente (en abstracto y en concreto) para alcanzar un fin mediato (la obtención de un título universitario), también puede ver qué es lo conveniente en relación al Último Fin (definición de lo bueno).

Revista Quaestio luris, vol.04, no01. ISSN 1516-0351 p.329-350 333 
Cualquier hombre, sin mayor esfuerzo, es consciente de que determinadas acciones (mentir, maltratar a los padres, matar a un inocente, etc.) son malas,...al menos, cuando lo sufre en carne propia: al que roba no le parece bien que alguien le robe, el que miente, no quiere ser engañado, etc.; prueba suficiente de que considera el robo, la mentira, etc., como un mal: algo que no debe hacerse.(2)

El hombre descubre, entonces, reglas de conveniencia de las acciones al Último Fin (de la bondad o maldad de sus actos), que son regla de su conducta, que ordenan su comportamiento. Este conjunto de reglas no es otra cosa que la ley moral. Aplica esta ley a la situación y dicta una "sentencia" que será la norma próxima del obrar moral: el juicio de la conciencia.

La inteligencia presentará esta sentencia a la voluntad. Siempre, ante una acción consciente, la conciencia la mostrará como buena o como mala. Y, si es buena, la presentará como obligatoria: "debes hacer tal cosa"; por el contrario, si es mala dirá: "no debes..." La voluntad se mueve libremente hacia ese bien presentado por la inteligencia, como a su objeto propio. La libertad es esta capacidad de autodeterminarse hacia el bien. El hombre no es movido por la cosa exterior, fin de su acción, sino que se mueve a sí mismo, se autodetermina (es causa de sus actos, dueño de ellos y, por lo tanto, responsable). Los animales, en cambio, son movidos por el objeto exterior que se presenta a sus sentidos y mueve a sus instintos necesariamente, no tiene dominio de sus actos. En efecto, si a un perro con hambre le ponemos delante un trozo de carne, lo come, no es capaz de hacer otra cosa. En cambio, si una chica está haciendo una dieta para adelgazar y tiene ante ella una deliciosa torta de chocolate, puede abstenerse de comerla, aunque tenga hambre, porque la inteligencia le mostrará que no es conveniente para tener una buena silueta.

La voluntad podrá seguir la indicación de la conciencia o no. Pero no por eso cambiará la ley moral (así como sigue siendo conveniente estudiar para recibirse o no comer torta para adelgazar, aunque uno no lo haga, así también sigue siendo malo matar a un inocente aunque uno lo mate). Y no por eso el bien pierde su carácter obligatorio. Por eso el hombre se queda con una gran paz cuando elige el bien (es la felicidad de haber alcanzado ese bien), y, en

Revista Quaestio luris, vol.04, no01. ISSN 1516-0351 p.329-350 334 
cambio, cuando no sigue el juicio de la conciencia, con remordimiento (no alcanzó la felicidad pues la buscó donde no estaba).

Ya dijimos varias veces que la ley moral se presenta, a través del juicio de la conciencia, como algo obligatorio. Incluso hemos recalcado la palabra "debes" con que empieza la sentencia de la conciencia, para subrayar esta obligatoriedad. Nos detendremos, ahora, un poco más sobre este punto porque es de vital importancia para el tema que nos ocupa.

Obligatorio es distinto de necesario (pues cabe la posibilidad física de no hacerlo), pero también es distinto de indiferente. La inteligencia no le dice a la voluntad: "puedes hacer esto o no indistintamente", sino: "tienes que hacerlo, porque debes hacerlo, aunque puedas (físicamente) no hacerlo".

Vimos otra manifestación de la obligatoriedad del juicio de la conciencia en el remordimiento que sigue a la desobediencia al dictamen de aquélla.

Pero ¿en qué consiste este "deber", esta obligatoriedad de la ley moral? "Obligar" viene de "ligar". Y así "como quien está atado (ligado) no puede dirigirse a otro lugar, a menos que arranque las ligaduras, deformando los miembros que están sujetos",(3) así también la ley moral obliga al hombre en el sentido de que no puede "desligarse" de ella, no seguir su mandato presentado por el juicio de la conciencia, sin incurrir en deformidad, sin ir contra su naturaleza. En efecto, cuando el hombre se deja guiar sólo por los sentidos, prescindiendo de la proporción al último fin que guarda ese acto, comienza a comportarse como los animales, que siguen necesariamente el ímpetu de sus pasiones. Y esto es ir contra su naturaleza, que es racional.(En el ejemplo de la chica que tiene adelante la torta, si la come a pesar del dictamen de la razón, es porque "no se pudo dominar", es decir, "se asemejó" un poco a los animales que no son dueños de sus actos).

Por lo dicho, la ley moral obliga. Pero, además -y esta es una afirmación fundamental para el tema de las relaciones entre moral y derecho-, no cabe otra posibilidad de obligar a nuestra libertad. Y esto es así porque sólo el Bien Absoluto, el Fin Ultimo, se presenta imperativamente a la voluntad como su fin adecuado, con la fuerza del Absoluto Bien; pues

Revista Quaestio luris, vol.04, no01. ISSN 1516-0351 p.329-350 335 
lo único que el hombre no puede no querer es ser máximamente feliz -y ya vimos la relación entre la felicidad máxima y el Sumo Bien o Fin Último-. Los demás fines, entonces, imperarán a la voluntad en cuanto estén ordenados a este Último Fin (en cuanto sean moralmente buenos). 2 Hemos descubierto la existencia de la ley moral; hemos delimitado su concepto; hemos visto algunos de sus preceptos fundamentales fácilmente alcanzables con la luz de la inteligencia (el más evidente y primero: "hay que hacer el bien y evitar el mal", pues sólo el bien se presenta como obligación; y otros como "no matar al inocente, no robar, no mentir, no maltratar a los padres, etc." -que tienen también su enunciación positiva); hemos analizado la fuerza obligatoria de la ley moral.

Estamos en condiciones de dar una definición de ley moral y precisar sus características fundamentales.

\section{Definición:}

La ley moral es un ordenamiento del comportamiento humano (de los actos humanos, libres), en relación (es el criterio del ordenamiento) con la bondad o malicia de esos actos (con su ordenación al Fin Ultimo).

\section{Características:}

- La ley moral que estamos considerando es una ley moral natural, pues está inscripta en la naturaleza del hombre (partimos de su modo de ser del que se seguía su modo de obrar). Como el hombre es por naturaleza inteligente y libre, esta ley respeta este modo de ser. Está inscripta en su voluntad libre como una tendencia interna hacia el Sumo Bien (la perfección), como obligación, pero no como una necesidad: el hombre la sigue libremente, a diferencia de los seres irracionales que cumplen sus leyes propias necesariamente. Está inscripta en su inteligencia: en cuanto que es capaz de descubrir esta ley, no la sigue ciegamente, sino que ve el fin de sus actos y su relación con el Ultimo Fin.

- Como en lo esencial el hombre no cambia (siempre será un animal racional, con inteligencia y voluntad libre), esta ley será universal: válida para todos los hombres de todos los tiempos y culturas y cognoscible por todos.

Revista Quaestio luris, vol.04, no01. ISSN 1516-0351 p.329-350 336 
- $\quad$ Repetimos que es objetiva, no la inventa el hombre sino que la descubre y aplica (como tampoco inventa el estudiante que para recibirse debe estudiar).

- $\quad$ También por naturaleza, el hombre es social (Aristóteles decía que el hombre es un animal político): necesita de los demás para alcanzar su Ultimo Fin, su pleno desarrollo (su

perfeccionamiento). Es evidente que necesita de los demás, primero, para nacer; luego necesita de una familia para crecer, alimentarse, recibir una educación apropiada, etc.; necesita de los demás para desarrollar su inteligencia, para aprender (¡qué pocas cosas sabríamos si no hubiéramos tenido alguien que nos enseñara!); necesita de los demás para desarrollar su capacidad de amar; y el mismo lenguaje es una manifestación clara de esta sociabilidad natural del hombre.

Por ser natural, entonces, esta ley moral alcanza a los actos humanos desarrollados en el ámbito de las relaciones interpersonales, que es el propio de la vida en sociedad.

\section{DERECHO: CONCEPTO Y FUNDAMENTO.}

El derecho es también un ordenamiento del comportamiento humano intersubjetivo (actos humanos, libres, con los que el hombre se pone en relación con otras personas), pero ¿según qué criterio?

2 El iuspositivismo pretende no sujetarse a ningún criterio (para evitar toda contaminación metajurídica), y sostiene que es derecho aquel ordenamiento que está vigente. En la realidad, esto equivale a erigir como criterio de lo que es derecho, el arbitrio del legislador y la imposición por la fuerza (coerción) de esta voluntad.(4) Las consecuencias nefastas de esta postura quedan patentes en los crímenes de lesa humanidad de la Alemania nazi. En los juicios de Nüremberg se vio la necesidad de volver al derecho natural: aunque los criminales

Revista Quaestio luris, vol.04, no01. ISSN 1516-0351 p.329-350 337 
de guerra nazis hubieran actuado de acuerdo con el derecho vigente en Alemania entonces, y aunque la ley penal (salvo que sea más benigna) es irretroactiva, era evidente que su actuación era contraria a derecho, al haber violado derechos inherentes al hombre.

Por otra parte, el reconocimiento internacional de los derechos humanos exige el retorno a la naturaleza del hombre y al derecho natural como a su único fundamento posible.(5)

2 El iusnaturalismo o doctrina del derecho natural, entiende por derecho un ordenamiento social (o del comportamiento humano intersubjetivo) justo.

Es derecho la norma (escrita o consuetudinaria), la facultad (o derecho subjetivo) y la misma cosa justa,(6) lo justo y, más profundamente, lo justo natural (que será igual entonces a derecho natural). Este último es el sentido principal, el meollo, el criterio por el cual un determinado ordenamiento social podemos decir que es derecho: es derecho porque tiene algo de esa cosa justa, aunque no todo. (¿Por qué, si es el criterio y el fundamento del derecho le llamamos "derecho"? Ya volveremos luego sobre este punto).

- $\quad$ ¿Pero qué es lo justo?

2 Evidentemente, hace relación a la justicia. Esta, en definición de Ulpiano, es la "constante y perpetua voluntad de dar a cada uno lo suyo", lo que le corresponde, o lo que le es debido, o su derecho.

Es posible distinguir la obra justa (la acción que consiste en dar a cada uno lo suyo) de la persona justa.(7) Por ejemplo: decimos que un profesor es justo cuando tiene esa "perpetua y constante voluntad de dar a cada uno lo suyo", cuando habitualmente pone a cada alumno la nota que se merece; pero si un profesor aplaza injustamente a un alumno, aunque éste luego recurra la decisión y obtenga que por una resolución del Consejo de la Facultad el profesor le 
dé por aprobado ese examen, diremos que este profesor es injusto, aunque haya cumplido con la obra justa dándole al alumno la nota que se merecía.

En el ámbito de la moral se exige tanto el ánimo justo como la obra justa. La acción moralmente justa hace bueno (justo) al que obra y buena (justa) la obra. Vale decir que la moral exige la plena perfección del acto: la perfección objetiva y la subjetiva. (8)

En cambio el derecho rescata como un valor (pues es un factor -y criterio- de orden social) la obra justa, independientemente del ánimo del que la realiza. Sólo exige esa perfección disminuida objetiva. Esta es una primera delimitación de lo que es la cosa justa.

2 "Puesto que el acto de la justicia es dar a cada uno lo suyo, todo acto de justicia debe estar precedido de un acto por el cual una cosa pasa a ser pertenencia de alguien; como se ve en las cosas humanas donde uno, con el trabajo, hace suyo lo que después el remunerador, con un acto de justicia, le da". (9)

Y bien, esa "adecuación o pertenencia de alguna cosa a alguien puede originarse en la naturaleza de la cosa" (el acto por el que se le da como suyo el derecho sería la misma recepción del ser en un modo de ser del que se sigue un modo de actuar -naturaleza-) "y entonces tenemos el derecho natural; o en lo establecido, que puede ser privado (contrato) o público (ley), y entonces estamos en el derecho positivo". (10)

Lo primero suyo del hombre es "lo que el hombre es". Es el punto de partida y el motor de lo que será (potencia activa en la que está contenida su perfección futura). Por eso el primer derecho del hombre es que se lo respete en su calidad de tal: respeto de su libertad proyectada a todos los ámbitos del bien que exige su naturaleza: a la conservación propia (derecho a la vida, a la propiedad, etc.); a la conservación de la especie (derecho a la procreación y educación de los hijos, libertad de educación, derecho al marco estable necesario de una familia, etc.); a la vida en sociedad (derecho de asociación, de reunión, etc.); al conocimiento de la verdad (derecho a la libertad de pensamiento, expresión, 
información, etc.) y al conocimiento y relación con Dios, suma Verdad y Ultimo Fin del hombre (libertad de culto).

Lo suyo natural (o derecho natural) se desprende, pues, de lo que el hombre es, de su esencia (esencia en cuanto principio de operaciones, es decir, naturaleza).

Pero, en el ámbito de lo justo establecido, el criterio y fundamento del derecho sería, igual que en el positivismo jurídico, su positividad, la voluntad del legislador (o de los contratantes).

Esto sería cierto si entendiéramos el derecho natural y el positivo como dos bloques yuxtapuestos o contrapuestos. Sin embargo, veremos cómo son, en cambio, "dos tejidos sólidamente trenzados en el mismo organismo: (...) el derecho natural es la raíz de la cual vive, la base sobre la cual se erige el derecho positivo".(11)

Por eso dijimos que lo justo, como criterio y fundamento del derecho, es "más profundamente" lo justo natural, el derecho natural.

2 Ya veremos cómo se da este entrelazamiento, cómo el influjo del derecho natural llega a todo el ordenamiento jurídico. Pero antes, para terminar de definir lo justo y poder pasar de este fundamento a la totalidad del edificio, acudiremos a la ley como puente entre lo justo y la totalidad del ordenamiento.

¿Cuál es el concepto de ley jurídica?

Lo justo es "res iusta", "cosa" justa, en primer lugar, para subrayar que la acción que tiene por objeto esta cosa justa (la acción justa) interesa al derecho en su exterioridad, independientemente del ánimo justo de quien la realiza, pues "nuestros actos, separados del ánimo, caen al nivel de las cosas".(12) Lo justo, lo debido, será, por ejemplo, la parte de impuestos que debo pagar, la calificación que debe poner el profesor: una cosa o una acción exterior concreta. Por eso, en segundo lugar, se habla de "cosa" justa para recalcar que es algo que pertenece al mundo real, a la realidad exterior, es algo objetivo.

Revista Quaestio luris, vol.04, no01. ISSN 1516-0351 p.329-350 340 
Sin embargo, esta cosa justa no es una cosa bruta, sino que es una cosa "justa", "debida", lo cual indica una proporción a otro, una relación entre más términos; relación que está "radicada en las cosas", pero que sólo puede ser descubierta por la razón y que, por lo tanto, también "existe, de modo más sutil e ideal, en la mente que la contempla".(13)

Así, esta cosa justa recibe una "expresión consciente, expresión que llamamos ley".(14) "Sin esta expresión racional, las relaciones de igualdad (de justicia) permanecerían en estado ciego y mudo, encerradas en las cosas",(15) incapaces de influir como criterio ordenador en el campo de la actuación humana; porque el hombre, para moverse a actuar, necesita que la inteligencia le exprese esa exigencia de las cosas como exigencia de su actuar (como bien conveniente a la voluntad).

2 Ahora sí veremos cómo se entrelazan el derecho positivo y el derecho natural y cómo este último es el fundamento de todo el ordenamiento jurídico.

Lo justo natural es expresado por la ley natural.

Dentro de la ley natural podemos distinguir tres sectores, que, como veremos, se corresponden con otros tres del ordenamiento jurídico positivo.(16)

$1^{\circ}$ ) En el primero están aquellas exigencias de la naturaleza, con una expresión consciente en la inteligencia humana, que por sí solas son aptas para regular la vida social. Así, siguiendo el ejemplo que pone Graneris, si "dos personas no ligadas por ninguna relación de derecho positivo se encuentran en lo más tupido de una selva tropical (...), cada uno de ellos estará protegido por la naturaleza con el derecho a la vida y con el consiguiente deber recíproco de mutuo respeto; deber y derecho tan unidos y tan enérgicos que si uno de los dos desconocidos desatiende el propio deber y agrede al otro, éste puede defenderse reaccionando incluso con la violencia y aun con la muerte del agresor (...) -según el principio, admitido universalmente, [de la legítima defensa]-".(17) Así, el derecho a la vida regulará su conducta, será una norma de su comportamiento en sus relaciones recíprocas.

Nada falta a esta situación de derechos y deberes recíprocos para su plena juridicidad, para ser apta para regular la vida en sociedad. Incluso cabe, como vimos, la posibilidad de la 
coerción a través de la legítima defensa. (Se dan todas las características que los juristas exigen para la juridicidad: alteridad, exterioridad y coercibilidad). Por eso llamamos "derecho" al derecho natural, a lo justo natural.

$2^{\circ}$ ) En una segunda zona, el derecho natural (las exigencias que surgen de la naturaleza de las cosas) nos da normas con límites imprecisos, que exigen una delimitación ulterior por el derecho positivo para poder regular la vida en sociedad. Así, por ejemplo, la norma de derecho natural dirá: "al homicida debe imponérsele una pena"; pero no determinará el tipo ni la duración de la pena.

$3^{\circ}$ ) En un tercer sector, el derecho natural, a primera vista, parecería que no dice nada, y el derecho positivo es plenamente libre para determinar lo justo.

Así, por ejemplo, si preguntamos a la naturaleza de las cosas si los autos deben circular por la derecha o por la izquierda, no nos dirá nada, es indiferente una u otra solución.

Sin embargo, si analizamos el punto con mayor profundidad, veremos que también en este sector el derecho natural tiene su influjo, influjo que es formal y de contenido.

En efecto, el derecho natural dirá que es indiferente que se conduzca por la derecha o por la izquierda, pero también dirá que, una vez que el derecho positivo defina el punto, ya no será más indiferente. Aquí el influjo del derecho natural será de carácter formal, pues la naturaleza nos da una norma vacía que es llenada por el derecho positivo. Esta norma formal dice "hay obligación de obedecer al legislador". Y es una norma de derecho natural pues se desprende de la naturaleza social del hombre, según la cual éste vive en sociedad, y la autoridad y el deber de obediencia a la misma son elementos imprescindibles para la existencia de una sociedad.

Tampoco dirá el derecho natural, siguiendo el ejemplo que pone Graneris,(18) si el plazo para interponer un recurso de apelación debe ser de diez o veinte días, pero sí fijará unos límites de razonabilidad para que se salvaguarde el derecho natural de acceso a la justicia y la necesidad (también de derecho natural) de poner término a los pleitos. Aquí el influjo del derecho natural llega al contenido de la norma como límite del arbitrio legislativo: el plazo de la apelación podrá ser de diez o veinte días, pero no de tres minutos o de cien años.

Revista Quaestio luris, vol.04, no01. ISSN 1516-0351 p.329-350 342 
Es clara la misión de la ley positiva en el segundo (delimitación de lo justo natural) y tercero (determinación) de los sectores vistos. Pero también en la primera zona tiene su función (expresión): al expresar verbalmente el mandato que surge de la naturaleza de las cosas, lo hace más accesible a los espíritus distraídos; además, al predeterminar el modo de punición y constricción del organismo social, refuerza aquel mandato.

Ahora sí podemos apreciar la interrelación entre la ley natural y la ley positiva. La primera es una expresión consciente, pero no escrita, de lo justo (derecho) natural: no es un código, pero tampoco es un mero ideal, sino que está presente, como fundamento y como savia, en los concretos ordenamientos jurídicos. La ley positiva -escrita, codificable- en cambio, determina lo justo positivo, el derecho positivo, pero siempre está penetrada de ley natural.

\section{RELACIONES ENTRE MORAL Y DERECHO:}

Antes que nada, una aclaración: cuando hemos hablado de "moral" nos hemos referido a la moral natural; cuando hablemos de "derecho", nos referiremos al ordenamiento social justo, a un todo que se nos presenta como derecho positivo pero que tiene como fundamento el derecho natural (que por ser natural tendrá las mismas características -universalidad...- que vimos que tenía la ley moral natural por ser natural).

2 En primer lugar, afirmaremos la moralidad del derecho. Y esto lo haremos por dos vías

Revista Quaestio luris, vol.04, no01. ISSN 1516-0351 p.329-350 343 
$1^{\text {a) }}$ En su aspecto más externo, el derecho se nos presenta como mecanismo coactivo imperativo que tiende a hacer obrar al hombre. Y "así como no podemos utilizar las fuerzas naturales [-por ejemplo, en una central hidroeléctrica-] si no es obedeciendo a sus leyes" (20) así también, para hacer obrar al hombre hay que tener presente la naturaleza de su obrar, que está regido por normas éticas. Si no se respetan estas normas, se producirá en el hombre una tensión que paralizará la eficacia del derecho.

$2^{\mathrm{a}}$ ) Desde un punto de vista más profundo, el derecho -como hemos visto- tiene como fundamento la cosa justa, lo debido. La cosa justa nace del seno de la justicia y, por lo tanto, de la moral; el deber emerge siempre de la moralidad (afirmación que ya probamos y en la que insistimos reiteradamente al tratar el concepto y el fundamento de la moral).

"Este nexo originario entre moral y derecho, no permitirá nunca escisiones objetivas": a través de lo justo, el derecho bebe en sus raíces "la savia de la moralidad",(21) que luego llega a todas las ramas del ordenamiento jurídico; si la cosa justa fuera inmoral, no sería justa, y si un ordenamiento no es justo, no es derecho.

De esta afirmación inicial de la moralidad del derecho se desprenden algunas conclusiones prácticas:

a) Las normas de derecho no pueden ser inmorales (contrarias a la moral).

b) Además, como objetivamente las normas jurídicas tienen un contenido moral, son una guía, una manifestación de la moral. Por eso el derecho tiene una función pedagógica ejemplar (el común de la gente considera que si el derecho manda algo, eso es moral).

c) Incluso, mediante ciertas formas de coacción, puede lograrse "vencer la rebelión del sujeto pasivo de la misma, haciéndole conquistar el hábito de la obediencia a la ley. Pero ésta es una atención lejana del legislador y de la ley, cuya finalidad inmediata queda en obtener la acción a cualquier precio, logrando que los rebeldes sean no mejores, sino simplemente inocuos." (22)

d) Otra consecuencia de la moralidad del derecho (en su totalidad, y no sólo en la aplicación inmediata de los principios de derecho natural) es su obligatoriedad (también en 
su totalidad) como ley moral. Hay obligación moral de cumplir el derecho (el derecho justo, valga la redundancia).

Pero el hecho de haber afirmado la moralidad del derecho no signigica que moral y derecho se identifiquen:

$1^{\circ}$ ) Por su ámbito: la moral regula todos los actos humanos (libres); el derecho, sólo aquéllos en que entran en relación dos personas y está en juego lo justo.

Hay, entonces, un ámbito de las normas morales que no coincide con el ámbito del derecho, y escapa, por tanto, a su competencia: no todo lo inmoral está prohibido por el derecho ni todo lo moral está mandado por el derecho. No lo estará si no se trata de actos en los que entran en relación dos o más personas y en los que está en juego lo justo.

Por lo tanto, no podrá ser jurídica una ley que regule actos meramente interiores. (Sin embargo, sería falso decir que ella tiene por objeto sólo actos externos, pues tales actos no serían humanos, es decir, estarían sustraídos a nuestro dominio, y así resultaría absurda la pretensión de regularlos).

El artículo 10 de la Constitución de la República recoge con claridad este principio: "Las acciones privadas de las personas que de ningún modo atacan el

orden público ni perjudican a un tercero, están exentas de la autoridad de los magistrados".

$2^{\circ}$ ) Aún en el mismo ámbito donde coinciden los dos ordenamientos,

- $\quad$ la ley moral exige la perfección completa (objetiva y subjetiva) del acto justo (pues mira a la ordenación al Fin Ultimo que, como el hombre es libre, se realiza si él ordena el acto -objetivamente justo, ordenable- hacia tal fin). La ley jurídica, en cambio, exige sólo la perfección objetiva del acto justo (pues mira a la creación de sólo las condiciones exteriores para que el hombre en sociedad alcance el Ultimo Fin, en la medida en que tales condiciones son exigibles por otros), independientemente del ánimo (justo o no) con que se realice.

Kant decía que "la ley moral manda el deber y determina también el motivo (impulso) por el cual debe hacerse; la ley jurídica, en cambio, ordena sólo el deber y se desinteresa del motivo por el cual será hecho." (23)

Revista Quaestio luris, vol.04, no01. ISSN 1516-0351 p.329-350 345 
El acto justo conserva un valor para la sociedad, pues alcanza para lograr ese orden exterior que es el fin de la misma. De esta forma concretamos más en qué actos se pone en juego lo justo: sólo en "aquellos actos que conservan un valor aunque se ejecuten con una glacial postura interior. Así, por ejemplo, una norma que dijera que los cónyuges se deben amor mutuo, fidelidad, asistencia y socorros recíprocos (...), sería jurídica en relación con los tres últimos deberes (...), pero no en relación con el amor, pues se ama "ex animo" -con ánimo de amar- o no se ama". (24)

El derecho no busca, en quien debe cumplir la norma, que sea bueno, sino que deje ser bueno a los demás.

- $\quad$ Además, se da en el derecho una imposibilidad congénita -por los medios de que dispone- para ajustarse objetivamente a la cosa justa natural con total perfección:

Para ordenar la convivencia social necesita normas generales y de cierta rigidez (incapaces de contener la infinita riqueza de la realidad regulada) modelada en formas verbales (palabras). Y así "recorta la realidad con esquemas preformados", con líneas netas cuando aquélla se dibuja con líneas no tan nítidas. (25)

Además, por la misma razón de orden, en el derecho es necesaria la intervención de terceros en su aplicación. Para seguir la cosa justa en toda su sinuosidad, sería necesaria una continua adaptación que exige, además de una norma más flexible, "una norma manejada por el mismo sujeto, que muchas veces es el único que conoce los matices y circunstancias decisivas" (26).

Así, puede ser que una ley justa en los casos generales, no lo sea en su aplicación a algún caso concreto.

También por esta necesidad de orden, se da en el derecho, a veces, como una aparente falta de justicia, sacrificada en pro de la certeza jurídica, necesaria para el orden.

Es lo que sucede en el caso de la prescripción adquisitiva (el poseedor, incluso de mala fe, si permanece treinta años en esta posesión pública, continua y con ánimo de propietario, se hace dueño del inmueble aunque haya un legítimo propietario con todos los títulos a su 
favor). Con la cosa juzgada sucede lo mismo: uno puede tener la verdad de su lado, pero si no la prueba, no se reconocerá su derecho ni tendrá luego posibilidad de probarlo.

En éstos, como en otros casos similares, si los contendientes vivieran aislados podrían darse el lujo de disputar hasta el infinito. Pero esta pretensión de ir "hasta el fondo" en la búsqueda de la solución justa para los individuos, resulta injusta para los demás, pues la prolongación de la disputa apareja incertidumbre y, consecuentemente, daño para muchos. Por eso, aquella aparente falta de justicia privada o abstracta, cede en favor de una justicia pública o concreta, que resultará de un análisis completo de la situación.

\section{CONCLUSIÓN:}

Hemos visto la ley moral y el derecho, fundados en la naturaleza del hombre (en lo que el hombre es). Esta raíz común no permitirá contraposición alguna entre el ordenamiento jurídico y el moral, ni una desvinculación total. Pero tampoco se pueden identificar: $1^{\circ}$, por su ámbito, gran parte de las acciones reguladas por la moral escapan a la regulación jurídica, y $2^{\circ}$, porque aun en el ámbito de coincidencia: a) la ley moral exige una perfección más plena de los actos humanos y el derecho sólo su perfección exterior, necesaria para el ordenamiento social, $\mathrm{y}, \mathrm{b}$ ) porque, por las necesidades y características de este ordenamiento, no se ajusta plenamente a las exigencias de justicia del orden moral.

\section{NOTAS:}

2 Cfr.GÓMEZ PÉREZ, Rafael. Deontología Jurídica. Ediciones Universidad de Navarra, S. A., Pamplona, 1982, págs. 23 y ss. y 81 y ss.

3 Sto. Tomás de Aquino, In II Sent., d. 39, q. 3, a. 3. , citado en GARCÍA DE HARO, Ramón. La Conciencia Moral. Ed. RIALP, S.A. Madrid. 1978. (pág 110).

${ }^{4}$ cfr. CASAUBÓN, Juan Alfredo."Hans Kelsen y la Teoría Pura del Derecho", en "Revista de Estudio Teológicos y Filosóficos (PP. Dominicos)", Buenos Aires 1961, t. III, nn. 2 y 3.

5 Cfr. - I diritti dell' uomo come rivoluzione etica. Sergio Cotta. Dixionario Critico della Filosofia d’Oggi (n. 60-61) págs 11 a 27.

- Nuova etica e diritti dell' uomo nella politica europea. Vittorio Possenti. Dixionario Critico della Filosofia d’Oggi (n. 60-61) págs 27 a 41.

6 Cfr. SANCHO IZQUIERDO, Miguel y HERVADA, Javier. Compendio de Derecho Natural. EUNSA. Pamplona 1980. T. I pág. 32 nota 47. 
7 cfr. GRANERIS, Giuseppe. Contribución Tomista a la Filosofía del Derecho. Editorial Universitaria de Buenos Aires. 1977. $2^{\text {a }}$ ed. págs 20 a 21.

$8 \quad$ Id.

9 Sto Tomás de Aquino, Contra Gentes, lib.II, c. 28, citado en GRANERIS, op. cit. pág. 24.

10 Cfr. Sto Tomás de Aquino, Summa Theol., I-II, 95, 2, citado en GRANERIS, op. cit. pág. 24.

11 GRANERIS, op. cit. pág. 25.

12 Id. pág. 23.

Id. pág. 30 .

14 Id.

15 Id.

16 Cfr. GRANERIS, op. cit. págs. 69 a $77 . \quad$ GRANERIS, op. cit. pág. 73.

$20 \quad$ GRANERIS, op. cit. págs 43-

44.

$21 \quad$ GRANERIS, op. cit. págs $44 .^{22}$

GRANERIS, op. cit. pág. 53.

23 KANT, Emmanuel. Metaphysik der Sitten, Finl., III, citado por GRANERIS, op. cit. pág. 47.

$24 \quad$ GRANERIS, op. cit. pág. 46.

25 Cfr. GRANERIS, op. cit. pág. 55. ${ }^{26}$ GRANERIS, op. cit. pág. 55.

\section{Bibliografía:}

- $\quad$ CASAUBÓN, Juan Alfredo."Hans Kelsen y la Teoría Pura del Derecho", en "Revista de Estudios Teológicos y Filosóficos (PP. Dominicos)", Buenos Aires 1961, t. III, nn. 2 у 3.

COTTA, Sergio. "I diritti dell’ uomo come rivoluzione etica". Dixionario Critico della Filosofia d’Oggi (n. 60-61) págs 11 a 27.

COTTA, Sergio. Derecho y Moral. (Conferencia pronunciada el 13 de enero de 1989 en el Centro Académico Romano de la SantaCruz), en Ius Ecclesiae, 2 (1990), pp. 419432. 
DEL PORTILLO, Álvaro. "Moral y Derecho", en "Persona y Derecho", T. I. págs. 493 a 500. EUNSA. Pamplona.

GARCIA DE HARO, Ramón. La Conciencia Moral. Ed. RIALP, S.A. Madrid. 1978.

GÓMEZ PÉREZ, Rafael. Deontología Jurídica. Ediciones Universidad de Navarra, S. A., Pamplona, 1982

GRANERIS, Giuseppe. Contribución Tomista a la Filosofía del Derecho. Editorial Universitaria de Buenos Aires. 1977. $2^{\mathrm{a}}$ ed.

- $\quad$ POSSENTI, Vittorio. "Nuova etica e diritti dell’ uomo nella politica europea".. Dixionario Critico della Filosofia d’Oggi (n. 60-61) págs 27 a 41.

- SANCHO IZQUIERDO, Miguel y HERVADA, Javier. Compendio de Derecho Natural. EUNSA. Pamplona 1980.

- $\quad$ VILLEY, Michel. Compendio de Filosofía del Derecho. EUNSA. Pamplona. 1981. 
Quaestio Iuris vol.04, nํㅜ. ISSN 1516-0351

Universidade do Estado do Rio de Janeiro- UERJ- Revista Quaestio luris, 2012

VILLEY, Michel. Método, Fuentes y Lenguaje Jurídicos. GHERSI Editor. Buenos Aires 1978. 